\title{
The Impacts of Small Business on Poverty Reduction in Eastern Cape Province, South Africa
}

\author{
Olusola Akinwale \\ Department of Development Studies, University of Fort Hare, \\ 1 King Williams Town Road, Alice, Eastern Cape, South Africa. \\ soladay0123415@yahoo.com
}

\section{Oluwasola Ogundiran}

Agricultural Extension, University of Fort Hare, Eastern Cape, South Africa ogundiranoluwasola@yahoo.com

\section{Doi:10.5901/mjss.2014.v5n15p156}

\section{Abstract}

\begin{abstract}
This study identifies the impacts of small business in poverty reduction. Small business plays a major role in rural livelihood. Even in the developed countries, small business contributes more to the economic growth. The study was carried out in Alice, in Eastern Cape provide of South Africa, where people seems to live under the pressure of poverty. Structured questionnaires were administered on twenty-five community members who operate small business. The result shows that small business makes important impacts on livelihoods and thereby serves as an eyes opener for those who view small business as merely a survival strategy. Small business operators have plotted their way out of the bondage of poverty even though it has been though due to many challenges. Conclusively, small businesses have helped to improve the standard of living. If better platform is given, their performance will be better than the present.
\end{abstract}

\section{Introduction}

Within the developed and developing countries of the world, it is now generally accepted by policy-makers at local, regional and national level, that small- medium sized enterprises are becoming increasingly important in terms of employment, wealth creation and the development of innovation (Shafeek Sha 2006:2). Rural areas in developing worlds also are part of this embracement. Accordingly, South African rural areas are important because over $75 \%$ of the population reside and derive their livelihoods there, while approximately $70 \%$ of these rural people are poor because of the inability of the rural economies to provide them with remunerative jobs or self-employment opportunities (Statistics South Africa 2012:3). The problem is also complicated by poor infrastructure profile of the rural areas. Rural areas are known to be most isolated and remote areas due to the nature of the infrastructure. These rural areas contribute less to the economy of the country and their low contribution remains a cause of concern.

On the other hand, small businesses contribute significantly to the nation's development and to local economies. More employment opportunities have been created through business worldwide. For example, in 2008 and 2009, small businesses have created job opportunities for a larger number of employees in Nigeria's rural areas increasing the economic growth of the country by eighty per cent (Victor, 2010:2). This research examined the impacts of small business on poverty reduction in Eastern cape, by focusing on small businesses in Alice. Alice is a small town under Nkonkobe Municipality in Eastern Cape Province of South Africa. The 2001 census, shows that Alice population stood between 11,000 and 14,000 as at 2001 (ASPIRE, 2011:2). The report clarified that, the above population figures only speak of those who lives in Alice. Eight per cent of the working force in Alice is employed under formal sector, twenty-eight per cent is unemployed, while a larger population of sixty-four per cent of the working age is economically inactive (ASPIRE, 2011:2).

\section{Problem Statement}

Poverty is the major problem identified in this research. Eastern Cape Province has the highest unemployment rate amounting to $48.5 \%$ compared to $34 \%$ for South Africa as a whole (ECSECC, 2000:5). This has contributed to high level of poverty in Alice, resulting to high crime rate, prostitution, armed robbery and various social vices. The most affected 
population are the youths, women and the old-aged people who continue to live in poverty.

\section{Objective}

- To assess the impact of small business on poverty reduction in Alice.

Specific objectives

- To examine the challenges faced by small business operators in Alice

\section{Literature Review}

Unemployment figures are on the rise and the gap between the rich and the poor is widening. It is important to promote an entrepreneurship culture for the creation of jobs. Small businesses are becoming the leading employers in the South African economy as many people are being retrenched in government jobs leading to low employment opportunities in the economy. In 2007 the total number of small businesses in South Africa stood at 2.4 million (registered and informal firms) and contributed about 27\% to 34\% to GDP (Trade \& Industrial Policy Strategy 2011:16). This section reviews literatures in its attempt to discover the current debates surrounding the contribution of small business to rural poverty reduction.

\subsection{Small Businesses}

There are many definitions regarding the meaning of small business, because there is no single economic variable perfectly expresses the concept. The problem involves selecting a unit of measurement, such as total assets, number of employees, volume of sales, or size of investment as well as a point of division between small and large. Small businesses can be classified as micro, very small, small or medium enterprises, following a complex set of thresholds (The National Small Business Act, in DTI 2008:2) According to National Small Business (Act 1996:2), small business means any entity, whether or not incorporated or registered under any law, which consists mainly of persons carrying on small business concerns in any economic sector, or which has been established for the purpose of promoting the interests of or representing small business concerns.

The World Bank defined small business as a business having up to 300 employees; the European Union defined it as having up to 200 employees. (OECD 2005:7) Although, both institutions described small business in a different way, but the important thing is that small business are entities with small employees. In some developed countries, enterprises with or fewer than 500 employees are usually considered small and medium enterprises, while the case is different in developing countries. In South Africa, enterprises with five or less employees, whose annual turnover is below the compulsory VAT registration limit, are occasionally described as small businesses (DTI, 2008:2). And such small businesses are the focus of this study.

\subsection{Small Business Policy in South Africa}

Based on opening domestic markets to the world, many countries have endeavoured to promote small business sectors and equip local firms against challenges. South Africa's small business policy is principally informed by the 1995 "White Paper on national strategy on the development and promotion of small business in South Africa" (TIPS 2011:20). The country has also developed institutions and agencies to support small businesses, with access to financial and business support. According to (TIPS 2011), South Africa's 1995 White Paper outlined, among other things, the need for the government to create an enabling legal framework, facilitate access to information and advice, boost procurement from small firms and to improve access to finance and affordable physical infrastructure. The policy also led to the 1996 National Small Business Act as well as the launching of Khula enterprise Finance Limited in the same year, to dispense both financial non-financial supports.

Despite various initiative over the 17 years aimed at both high end enterprise development and the reassurance of small enterprises, government support agencies and initiatives have less impact than intended (Timm 2011). Therefore, importance of funding and support initiatives towards the growth of small business has not had the desired effect in growing the small firm sectors. 


\subsection{Poverty}

Poverty and its effects are relevant to a significant proportion of the stories that dominate the daily news agenda. People are said to be poor if their income and resources are so inadequate, preventing them from having a standard of living considered acceptable in the society (Clarkson 2009:2)

Spicker (2007:5), outline three classes of poverty. The first class refers to poverty as 'material need'. That means poverty can be seen as lack of specific need; pattern of deprivation and; low standard of living.

The second-class describe poverty as the weakness on people economic circumstances that have to do with lack of resources and economic distance. The limited access of the poor to resources deprived them the capability to afford their needs (Spicker 2007:5). In the economic class, older people or disabled were deprived of their right to command resources and thereby remain poor.

Spicker (2007:5) figured the third class of poverty as problems arising from social relationship, which includes the social class dependency; social exclusion and; lack of entitlement. Therefore, this third class sees as poverty a situation where the capacity of the poor to promote their quality of life is obstruct by lack of the needed physical assets as well as skills.

According to Buvinic (2004:30), poverty is attributed to lack of ability to control a suitable strategy in the time of crisis. Individuals and households poverty is therefore result to lack of amenities that obstruct them to manage negative effects of external shock. Poverty is also a state of material and social deprivation that make individuals go below the social acceptable standard of living that make them to experience social deprivation in the society.

Poverty is capable of creating much injury to humankind in several ways. Narayam (2004) analysed the World Bank study on poverty, he said; poverty is accompanied with hunger, which is lack of food. Secondly, psychological dimensions like dependency, humiliation, shame and powerlessness are among products of poverty to the poor. Thirdly, poverty denied poor people access to basic infrastructure like roads transportation, especially in the rural areas like Alice. Another way that poverty hurt the poor people is through the thirst for literacy. More so, poverty places poor households and individuals in the state of poor health and illness. Lastly, the poor are unable to speak about income but rather speak on managing the little assets they have as the best option to cope with their vulnerable condition.

\subsection{The State of poverty in Eastern Cape}

Eastern Cape has been rated second among the poorest provinces in South Africa; having a poverty rate of 35.7\%. Leading on the rating table is the Limpopo province, with a poverty rate of $48.5 \%$ (Statistics South Africa 2012:11). According to Westway (2012), Seventy-three per cent of the rural people in the Eastern Cape were living on less than R300 per month in 2005/06, while more than half of them on less than R220 per month. The average rural income including Alice was R255 per month, which is well below the poverty line (R293 per month) drawn by the Presidency in 2008 (Westaway 2012). ASPIRE (2011:2); highlights that more than 50\% of the formal jobs that exists in Alice are provided by education sector particularly, the famous University of Fort Hare and the Lovedale College. In order to deal with the pressure of unemployment crisis, the majority of Alice residents therefore venture into small business. The majority of small business owners in Alice are women, because it is easier for women to swallow their pride when poverty strikes (Narayan 2000). In view of limited employment opportunities in Alice, small business may be the alternative means to create employment and thereby reduce poverty in the town. Small businesses in the rural areas are ways in which centralizing forces in the distribution of power in the society can be counterbalanced (Scott Holmes 2001).

\section{Theoretical Framework}

\subsection{Sustainable Livelihood Approach}

According to (Krantz 2001:6) The sustainable livelihoods idea was first introduced by the Brundtland Commission on Environment and Development as a way of linking socioeconomic and ecological considerations in a cohesive, policyrelevant structure. It was expanded in 1992 by United Nations Conference on Environment and Development.

A livelihood comprises the capabilities, assets (stores, resources, claims and access) and activities required for a means of living: a livelihood is sustainable which can cope with and recover from stress and shocks, maintain or enhance its capabilities and assets, and provide sustainable livelihood opportunities for the next generation; and which contributes net benefits to other livelihoods at the local and global levels and in the short and long term (Krantz 2001:6). This means, a livelihood implies that indicators of wellbeing are subjective. 
The IDS framework of 1998 on sustainable livelihood for poverty reduction accords the efforts of both Sen (1984; 1987), and Chambers $(1995 ; 1997)$ respectively. Sen refers to capabilities as a concept that is far beyond having more than material things and food but what people can do or acquire with their income. Five major indications for sustainable livelihoods were highlighted in IDS framework, they are creation of working days; poverty reduction; well-being and capabilities; livelihood adaptation, vulnerability and reliance and; natural resources. Therefore, Poverty reduction is the major evaluation of livelihood indicating that when capability is guaranteed, the level of poverty will be reduced in the society (IDS 1998:6).

The most valuable means to empower people is to broaden the range of strategy alternatives through diversification into livelihood options that actually minimizes vulnerability (Goldman 2000). The process of poverty reduction entails social policy measures in which people's wellbeing are positively affected. This can be through welfare services or by the implementation of good policies that can have optimistic impact on lives.

One of the strength of the sustainable livelihood Approach is that creates a complete view on what resources, or combination of resources, are important to the poor, including not only physical and natural resources, but also their social and human capital. Secondly, sustainable livelihood promotes the knowledge to identify the reasons behind poverty by concentrating on the various factors, at different levels that determines poor people's access to resources/assets of different kinds, as well as their livelihoods. Lastly, sustainable livelihood approach provides an accurate plan and channels to assess the direct and indirect effects on people's living conditions than, one dimensional productivity or income criteria.

On the other hand, sustainable livelihood has some weaknesses. According to Krantz (2001:4), none of the sustainable livelihood approaches really deal with the issue of how to identify the poor themselves. In the context of sustainable livelihood, resources and other livelihood opportunities are distributed locally and influenced by informal structures of social dominance and power within the communities themselves.

The basic idea of the sustainable livelihood approach is to start with a broad and open-ended analysis, but this requires a highly flexible planning situation which rarely exists. So, the best hope is to ensure that already identified/decided sector development initiatives fit with people's livelihood strategies and make them better at responding to the constraints and opportunities affecting the poor. Thus, the approach, or its elements, will useful to that end (Krantz 2001:5).

\section{Research Methodology}

This is a study that seeks to study social behavior. That is, the impact of small business on poverty reduction in Alice; a study that is qualitative in nature was carried out. Qualitative research is an effective method to study social life (Strauss and Corbin, 1990:17). As qualitative research is the best method to study human behaviour, the researcher therefore adopt qualitative. Primarily, field data collected from sample of selected respondents formed the basis of the study. The researcher went to the field-Alice town to gather information that are truthful and relevant to the study. Meanwhile, the researcher consulted some publications and books as a means for secondary information. Other relevant sources of information such as published data from Statistics South Africa were also consulted.

\subsection{Participants}

The population from which representative sample was drawn was from small business operators in Alice town. The concept of households was used as a unit of analysis and action. Because it is the unit that stood between the realities and choices perceived by individual members and the abstract level and constraints imposed by larger external societal, political, economic and social factors (Wolf, 1991 in Mtshali, 2002). Twenty-five respondents were chosen as the sample for this research since the research was more qualitative in nature and the field where data collection took place (Alice) is also a small town. Simple random sampling was adopted as the sampling method for this study. According to Thompson (2012:42), Simple random sampling was defined as a sampling design in which ' $k$ ' distinct items are selected from the ' $n$ ' items in the population in such a way that every possible combination of $k$ items is equally likely to be the sample selected.

\subsection{Sampling Procedure}

In the context of the study, the target is those small business holders who have been in the business field for about three years and above. This is because poverty is so complex in nature and cannot be measure in a short period. For sampling 
to be purposeful, maximum variation techniques must be used. Such technique involves selecting a large range of variation on the length of interest. Thus, the selected population comprises men and women, employed and unemployed; married and single as well as the divorced and widows. Accordingly, they were selected from market area in Alice Town. The targeted age group is from sixteen years among who are small business owners in Alice. Apparently, the questionnaire took fifteen minutes to answer.

\subsection{Instrument}

The study adopted a self-administered questionnaire as the data collection instrument. The questionnaire consist of open-ended questions which enabled the respondents to respond in their own words, as well as closed ended questions that provided the respondent with different options. This contained set of questioned that was presented to the respondents, while the researcher himself explained the purpose of the questionnaire. This technique was used because of interview bias and it also saves time. The researcher was available to assist respondents to make clarifications where necessary. The questions were brief and clear. Sensitive questions were avoided because it may be difficult for respondents to attempt and thereby give false information.

Household information is a social indicator and can be used for measuring standard of living. Therefore, the questionnaire contained information like; age, sex, as well as school enrolment status which forms part of the household demographic information. Information in the questionnaire is socio-economic impact activities of small business and the challenges that the business holders are facing as well as the expected supports that can improve their small business activities. The questionnaire also consists of livelihood activities and/or occupation - former activities that household members engaged themselves before going into small business.

\subsection{Data Analysis}

This study has shown that through small business, people can meet their basic needs; they can make savings as well as acquire properties. Small business goes far beyond a mere survival strategy for households in Alice. It is also a poverty reduction strategy. Small business has helped people to elevate their status regardless of gender especially in the midst of the socio-economic crises they found themselves. Evidences include the improvement on health security, food security, incomes, property as well as education for children among the households' participants. This study has reached its completion with the help of the personally administered questionnaires that was used to collect appropriate data. The random selection of twenty five respondents was done in Alice town in which the data analysis and presentation of the findings is done in this section. Presentations will be done graphically and complemented with explanations according to responses from the participants.

Table 1: Demographic characteristics of the respondents

\begin{tabular}{|c|c|c|c|c|c|c|}
\hline Age & Marital Status & Gender & Number of dependents & Educational level & No. of years in S.B & Estimated monthly income \\
\hline $16-$ above & Married & Male & 6 & Grade 8 & 2 & 17000 \\
\hline $16-$ above & Single & Male & 3 & Grade 8 & 4 & 21000 \\
\hline $16-$ above & Married & Female & 8 & Grade 7 & 4 & 2000 \\
\hline $16-$ above & Married & Male & 7 & Grade 8 & 2 & 18000 \\
\hline $16-$ above & Married & Female & 4 & Grade 8 & 5 & 6000 \\
\hline $16-$ above & Married & Female & 4 & Grade 9 & 3 & 13000 \\
\hline $16-$ above & Divorced & Female & 5 & Grade 7 & 1 & 15000 \\
\hline $16-$ above & Single & Female & 3 & Grade 8 & 5 & 18000 \\
\hline $16-$ above & Single & Female & 3 & Grade 8 & 2 & 17000 \\
\hline $16-$ above & Single & Male & 6 & Grade 9 & 3 & 10000 \\
\hline $16-$ above & Married & Female & 2 & Grade 8 & 2 & 8000 \\
\hline $16-$ above & Single & Female & 1 & Grade 8 & 3 & 3000 \\
\hline $16-$ above & Single & Male & 2 & Honours & 4 & 23000 \\
\hline $16-$ above & Married & Female & 5 & Uneducated & 6 & - \\
\hline $16-$ above & Married & Female & 4 & Grade 8 & 3 & 4000 \\
\hline $16-$ above & Married & Male & 4 & Honours & 3 & 15000 \\
\hline $16-$ above & Single & Male & 2 & Grade 9 & 2 & - \\
\hline $16-$ above & Married & Female & 3 & Grade 8 & 4 & \\
\hline
\end{tabular}




\begin{tabular}{|c|c|c|c|c|c|c|}
\hline $16-$ above & Married & Male & 6 & B.Ed. & 7 & 10000 \\
\hline $16-$ above & Single & Female & 5 & Masters & 2 & 30000 \\
\hline $16-$ above & Single & Male & 3 & Grade 8 & 6 & 18000 \\
\hline Below 16 & Divorced & Female & 4 & Grade 8 & 1 & 7000 \\
\hline $16-$ above & Divorced & Male & 1 & Grade 7 & 3 & 27000 \\
\hline $16-$ above & Married & Male & 5 & Grade 9 & 2 & 30000 \\
\hline $16-$ above & Married & Female & 2 & Grade 8 & 5 & 40000 \\
\hline
\end{tabular}

Although some respondents refused to give figures on their income, yet the information provided in table 1 shows that amounts differs from one respondent to another.

\subsection{Participants' Age and their family Status}

A percentage of four participants were below the age of sixteen years while ninety percent were above sixteen years. Percentage for women participants stood at fifty-six while forty-four percentages were men. This means, a distinct percentage of twelve stood between men and women who are small business owners in Alice town. Such a high percentage of women on small business in Alice prove right the argument of Narayan (2000) that "when poverty strikes, women easily swallow their pride". Women are ready to engage in any form of job to earn living. Respondents' age is between 16 and 50 years but one female, participants' age was below sixteen years. The percentage for married participants was fifty-two; thirty-six percent were single, while only twelve percent were already divorced. The family size of respondents in this study is within the range of one to seven with both children and other dependents, with the reason that most of the respondents cater for their extended family members. As it reflected in chapter two of this study that 'African society at large is organized around extended family especially in the rural areas which can actually place pressure to few people engaged in small business'.

Figure 1.Gender of the Respondents in percentage

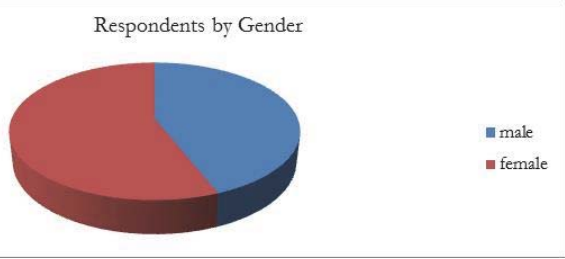

Table 2. Respondents' Educational Background

\begin{tabular}{|l|c|c|}
\hline Level of Education & Males & Female \\
\hline Secondary (grade 7-9) & 8 & 12 \\
\hline University Degrees & 3 & 1 \\
\hline uneducated & - & 1 \\
\hline Total & 11 & 14 \\
\hline
\end{tabular}

With indications from the respondents educational qualifications, this research have been able to prove wrong the notion of people that small businesses are meant for the uneducated people. The data collected for this study revealed that majority of people who people who engage in small business are educated. The information provided in table 2 shows that twenty respondents (Male and Female) representing eighty per-cent had secondary education. Four respondents representing sixteen percent had university education. Only one respondent, representing four percent of the respondents, are not educated. Based on the above analysis, small business is not only meant for uneducated people, but for the educated ones as well. 
Figure 2. Source of Capital in the Study Area

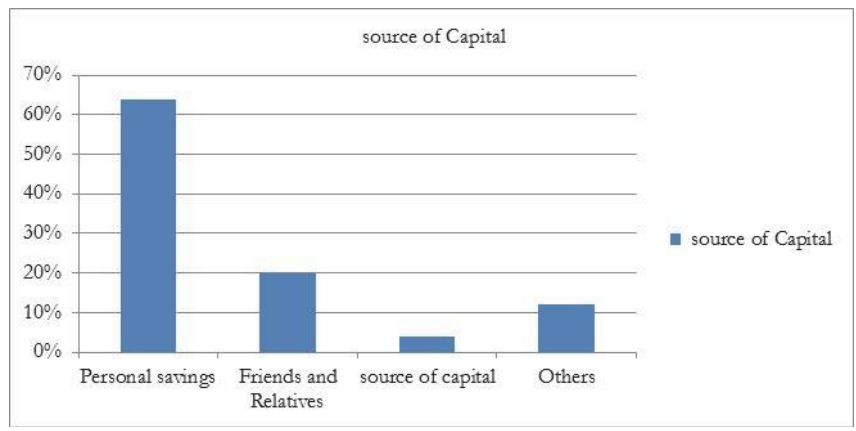

According to Fig. 2 the chat shows that initial capital for the small businesses in Alice acquired from various sources. Such sources includes, personal savings, loans from friends and relatives, bank loan as well as other credit facilities. Some of these business owners lamented that it was discouraging to acquire loan from bank due to the high interest rate placed on bank loans. The above chart shows that personal savings is the major source of initial capital for small business in Alice.

\subsection{Reasons for choosing small business}

Most of the participants emphasized that the motives behind their engagement in small business $\mathrm{s}$ to break out from poverty. They explained that they cannot fold arms while their family members die in poverty. In other words, they have to create a means for survival, as the Alice is a rural area with very limited formal jobs. This is in line with one of the factors in sustainable livelihood approach which advocates that the poor themselves often know their situation; needs best and must therefore be involved in the design of policies and projects intended to better their lot (LasseKrantz 2001:11) Meanwhile, some of them were schoolteachers, some are clerical workers, and some works as cleaners, while some are university students. Respondents who engage in other jobs like teaching, clerical works as well as those who are cleaners emphasized that they cannot rely on their salary alone because the cost of living continue to increase on daily basis. More so, they get more income in the business even more their formal jobs and some of them had quit those formal jobs to concentrate on their business. Those who are University students explained that there are no bursary opportunities for them; therefore they have to get something done to finance their education. One of them explained that the have been able to finance his education with profits from his business and even send some money to his old-aged parents at home as well as sponsoring two of his siblings in secondary schools. He also said he has been able to acquire some properties at his home country. Most of the respondents view poverty from the same perspectives saying, poverty is an illness to humankind. So for them to come out from such situation, they engaged in small business. All the respondents indicated that since they have started small business, there have been improvements in their lives in terms of better income, shelter, food security as well as property ownership. These improvements are therefore indicators for the impact of small business on poverty reduction.

\subsection{Business categories}

The business categories in this study includes the Pakistan groceries shops, hair making salon, phone sellers, and other traders who deals in selling clothes, shoes, jewelleries among many others.

\subsection{Respondents' views on poverty}

Although, quite a number of respondents viewed poverty from the same perspective that emphasizing on lack of shelter, food, and health yet there are differences from their ways of putting words together. In a nut shell, definitions are giving to poverty according to the respondents' experiences and understandings. Therefore, few of those definitions are highlighted below: 
"Poverty has to do with lack of basic needs like food, water, cloths and house"

"Poverty can be defined as when an individual is not able to have a three-square meal"

"Poverty is a situation where somebody is financially handicapped"

"Whenever a man is unable to provide for his family financially and materially, such family is said to be poor"

"Poverty is not only when someone cannot afford food and cloths, even if someone can afford all those things but cannot afford to buy card or build a house of his own"

The above definitions as given by respondents was due to differences in people's ideas, understanding and experiences on poverty, which shows that several meanings can be giving to poverty. This is in accordance with the notion of Spicker (2007:3) that, poverty in a multi-dimensional concept.

\subsection{Benefits of small business}

In second chapter of this study, Trade \& Industrial Policy Strategy (2011:16) analysed that small businesses contributed $27 \%$ to $34 \%$ of GDP in South Africa. Analysis in this study shows that small business plays crucial roles in poverty reduction, promote standard of living, and enhance well-being as well as moderating economic hardship in Alice. Because of their engagement in small business, people have improved on their health condition. For example, a respondent said that she can afford to take good care of her dependents, and whenever there is need to take them to the hospital for proper health care she never hesitated to do so. In terms of sponsoring child education, another respondent said he has been able to cater for his daughter's and a cousin's education up to college through the income from his business. Apart from being a poverty reduction small business creates employment because; by engaging in small business people who are jobless become profitably employed. From the results in this research, household incomes have increased through small business. It also plays a vital role in-term of empowerment, because it has become the only source of income to those who are not able to secure a space in the limited formal jobs; and to those who do other jobs, small business also serves as means additional income to them. With the capability derived from small business, some of the owners have reached a conclusion that; they can never lobby around any formal sector to hunt for employment. To crown it all, small business by increasing the employment levels, has enabled the reduction of poverty among the poor and also generates supplementary incomes for the already employed people in Alice. This research has, revealed that small business does not only comfort people in the state of poverty but takes them out of poverty predicament, which justifies that small business is truly a poverty reduction strategy in Alice.

\subsection{Challenges of Small Business}

The major challenge that could come to one's mind about establishing a business is finance. Initial capital has been the pioneer problem faced by majority of small business owners around Africa. Researches have revealed that it is the same situation in some other parts of the world. in countries like Ethiopia, Zambia and Tanzania the rate of initial capital generation for small businesses continue to increase from, 40\%, 54\% and 67\% respectively, (ILO 2004:40). This shows that in most of the African countries, small business owners generate their start-up capital from personal savings. Respondents shows that there are difficulties to acquire capital from bank, this therefore was the result of the higher percentage in the analysis for source of finance as shown earlier in this article.

Another challenge regards to small business is developing skills for start-up and know-how through training. Many people including the research of this study himself taught that there is no special training required before going into small business. But after the conduct of this research, it has come to be known that small business also requires skills which can actually be acquired if specific training is undergone. For example, a respondent that is the owner of a hair-making salon stressed that the job is not as easy as people think it is. Although it is a real money making business yet, one needs to undergo training. Before he established his own business, he went for two year training which he actually paid some money. Therefore, to develop the required skills for small business is among the challenges encountered by the small business owners, especially in Alice town.

Premises and equipment at start are also among the problem faced by small business owners in Alice. Most of the small business owners said it is difficult to afford the cost of available shops due to the high cost attached to it. This is great challenge on the small business sales and income, because majority of the customers prefers to buy from those big stores due to their packaging and people have access to pay through other means. For example, the town is majorly dominated by students who actually survives on bursaries that enable them pay through their students' account without cash at hand, therefore the small business owners especially those who deal in items that are sold in those big shops are 
likely to get lower income.

Vacation and holiday is one of the challenges highlighted. Alice, an environment dominated by students (especially the University of Fort Hare students). The business owners indicated that whenever it is vacation time for the students, the business is very cold in sales and most of the business owners even close their shops and relocate to other places to continue their business until the students resume. It a period of loss to their business because in spite of low sales they still have to pay the rents.

\section{Conclusion}

Based on the findings and discussions from this study, it is wise to that small business is a poverty reduction strategy seeing the fact that the respondents have able to break the yoke of poverty that has imprisoned their household. In addition, respondents' contribution to this study has helped to derive the fact that small businesses have impacts on poverty reduction. Although, those challenges facing the establishment of the businesses are hindrances to many people to venture into small businesses, which still contributes to poverty level in Alice and Eastern Cape in general. Yet, evidences from this study have shown that if supportive platforms are giving, small business will do well in as a means of reducing poverty.

Furthermore, Policymakers in South Africa need to focus on improving the collection and collation of statistics on small businesses in order to target more innovative, high-growth and knowledge-intensive businesses, which have been shown to create more sustainable jobs in the long term. Despites the negative assumptions that have already been attached to small business, the fact remains that small business has proved to deliver positive results on poverty reduction. Thus, Policy makers should avoid dialogues with the assumption that small business in not economically viable. Rather, much concern should be given to policies that can standardize the operation of small business.

\section{References}

Ashley Westaway (2012) Rural poverty in the Eastern Cape Province: Legacy of apartheid or consequence of contemporary segregationism? Development Southern Africa Journal: Routledge Publishing.

Aspire (2010) Alice Regeneration Strategy Programme: High level feasibility assessment report. AGN Design, Mowbray.

Department of Trade and Industry (2007).Integrated Strategy on the Promotion of Entrepreneurship and Small Enterprises. South Africa: DTI.

Frank SenaArku and Glen Filson with James Shute (2007) An Empirical Approach to the Study of Well-beingAmong Rural Men and Women in Ghana. Springer Science+Business Media. (31 October). 88

ILO (2004) The challenges of Growing Small Businesses: Insights from Women Entrepreneurs in Africa.Edited by, Pat Richardson. Geneva: International Labour Office.

ILO (2006) Poverty Reduction through Small Enterprises. Edited by Paul Vadenberg.: International Labour Office. Geneva.

Lasser Krantz (2001) The Sustainable Livelihood Approach to Poverty Reduction: An Introduction. Swedish International Development Cooperation Agency.

Mthali, SM (2002). Household Livelihood Security in Rural Kwa-Zulu Natal, South Africa. PhD Thesis, Wageningen University.

Narayan D, Patel R, Schafft K, Rademacher A, Koch-Schulte S (2000). Voices of The Poor: Can Anyone Hear Us? USA: Oxford University Press.

Ntsika (2002) State of Small Business in South Africa: Annual Review. Pretoria: Ntsika Enterprise Promotion Agency.

OECD (2004) Promoting Entrepreneurship and Innovative SMEs in A Global Economy: Towards a more Reasonable And Inclusive Globalization. Istanbul, Turkey: Organisation for Economic Co-operation and Development.

Paul Spicker (2007) The Idea of Poverty. Bristol, Great Britain: The Policy Press.

Statistics South Africa (2012) Poverty of South Africa: Application of the poverty line on LCS 2008/2009. SSA, Pretoria: ISBN 978-0-62141398-4.

Strauss A and Corbin J (1990) Basics of Qualitative Research: Grounded Theory Procedures and Techniques.Newburg Park, CA: Sage Publications, Inc.

Scott, Holmes (2001) Definition of Small Business -- Final Report on Small Business in Australia, April 5, 2001. Callaghan: University of New Castle.

Wolfensohn, J (2003) "Poverty is an issue of peace", Baylor Business Review, vol. 21, no. 1, pp19. 